\title{
Experimental Application of 3D Data to Inspection of Working Form
}

\author{
for River Works
}

\author{
Ryota KAKIMOTO ${ }^{1}$, Takuji NOMA ${ }^{2}$, and Ichiro KOBAYASHI ${ }^{3}$
}

\begin{abstract}
This paper presents an improvement of the duties process for working form in consideration of the characteristics of river works. Furthermore, two inspection methods are illustrated, one is distance-calculating method, other is coordinates- comparing method. And experiment is carried out at Yunoura river in the Kumamoto prefecture. Finally, we discuss about the result of test and show effectiveness and possibility of proposed methods.
\end{abstract}

Keywords : 3D data, Inspection method of working form, river work, Total Station,

Observational construction

\section{INTRODUCTION}

Improvement of the construction effectiveness with ICT becomes more necessary in recent construction industry. Civil engineering works are divided into the following phases; exploration, surveying, design, construction, inspection, and maintenance. Seamless use of information through each phases makes the works more efficient. Then, sharing and accumulating of the information of the construction life cycle are the most important because the control of the shape data of the structure has a great influence on each processes.

The shape data has been generally operated by 2D data and there is a problem in the sharing of the information through each processes. On the other hand, measurement equipment and $\mathrm{CAD}$ are getting applicable to the surveying and the design by 3D design. It means the control of the information by $3 \mathrm{D}$ data is possible at the construction life cycle by using them.

The Ministry of Land, Infrastructure, Transport and Tourism is started to deal with these problems, and a lot of construction contractors are doing the approach of the inspection work improvement using the total station ${ }^{1)}$ (TS) in the road works. The review of the construction process by using 3D data and the development of the data model of the construction data control are done in the road works ${ }^{2) 3 \text { ) }}$ 4)5).

On the other hand, the research of river works is not advanced because the form of the river is much more complicated than that of the road. It is difficult to describe its form by 2D or 3D data. working form with TS in river works and had proposed to introduce two methods; Distance Calculating Method (DCM) and Coordinates Comparing Method (CCM). The concept of DCM is very close to the current method and can be applied easily in practical use. The concept of CCM is quite different from the first one while using the same data as DCM. And it requires some modifications of current control standard for its practical application. However, CCM can be much useful for construction process improvement in the long-term. The objective of our research is exactly that.

Firstly, this paper proposes a two-phased improvement of construction process with 3D data in consideration of the characteristics of river works. Secondly, the result of experimental applications of the methods is presented. For the applications, we especially focused on the inspection of working form for a clear discussion. Finally, we discuss about the results and show effectiveness and possibility of proposed methods.

\section{CHARACTERISTICS OF RIVER WORKS AND INTRODUCTION OF 3D DATA CONTROL}

In current river works process, the dimension of data is converted frequently between 3D and 2D: Designers express their image of shapes into 2D data, planes and transverse sections. Therefore, 3D data which are stocked by exploration and surveying using TS are converted 2D planes. Then constructors reconvert the planes to 3D data. Moreover, in inspection of working form (checking completed structures' shape), they measure 2D data such as height or length to compare with design data.

Writers had discussed on methodology of inspection for

1) Member of JSCE, Kumamoto University (2-39-1 Krokami, Kumamoto 860-0855, Japan)

2) Civil Engineering Office, Kumamoto City Area, Kumamoto Prefectural Government (3-11-63 Higasimachi Kumamoto 862-0901, Japan)

3) Member of JSCE, Ph.D., Kumamoto University (2-39-1 Krokami, Kumamoto TEL 096-342-3531) 
Standardization of all the data in 3D considering characteristics of river work facilitates these information exchanges.

\section{(1) Characteristics of river works}

\section{a) Construction process}

The characteristics of river works in the construction process are as follows.

(1)After the revision of the River Act, engineers have to consider not only the disaster prevention but the environmental maintenance. Many free hands are given at an execution stage for engineers. In this process, communication among engineers, designers and constructors become important in comparison with the past. (2)As for the roadway design, centerline is the base line element. In river design, structures are much more complex because of the difference of base line between right bank and left bank.

(3) On stake installation, measurement of distance using tape from roadway centerline is very easy. But for river construction, centerline is not clear because it is in the middle of river which has water flow.

(4)There are a number of small-and-medium-sized rivers which have not ledger. It means that the completed structural data for maintenance are lucked.

\section{b) Small-and-medium-size construction site}

In Kumamoto prefecture, the execution rate of the river maintenance is $50.3 \%$ in 2005 . Therefore constant number of river maintenances will be done continuously in the future. The improvement of construction and inspection method using ICT might be applicable to such construction site for prefecture level and municipality level.

\section{(2) Analysis of introduction for 3D data control} a) Advantage of $3 \mathrm{D}$ data control

According to the characteristics of river works as mentioned in the preceding section, the advantages of introduction for 3D data control are as follows.

(1) 3D design data can be efficiently diverted to the presentation material such as movies and still pictures, and can be expected as the visual communication tool among engineers and workers related to construction.

(2)It becomes easy to get the data like transverse figure of arbitrary section. The improvement of the control effectiveness can be expected.

(3) Stake installation and measurement of width of a river based on three dimension coordinates (3D coordinates) become possible by using measurement equipment like TS. Then the construction effectiveness is improved.

(4)Working form surveying data can be diverted as the completed structural data by getting 3D coordinates in working form control.

\section{b) Problem of 3D data control}

The following problems are enumerated for the introduction of 3D data control.

(1) 3D design of the river is difficult unless using 3DCAD which is corresponded to $3 \mathrm{D}$ design of roadway because design of river structure is complex and flexible.

(2) Current inspection items are length, height, width, thickness and inclination of structure. Compared with it, 3D coordinate is not intuitively understood because they are point data.

\section{c) Introduction of 3D data control}

There is a problem because $3 \mathrm{D}$ design of river structure is very difficult without 3DCAD. It is desirable to achieve in the processes other than the design.

On the other hand, it is comparatively easy to use 3D data for the shape control of the structure like stake installation and inspection of working form. Then simplification of the measurement work and unification of the measurement method are expected.

It proposes to introduce 3D data control of river works in two steps as follows (Fig.1).

STEP1: The diffusion of 3D data use is made a main goal. Feasible and effective 3D data is handled in a current design method and control standard.

STEP2: Consistent data is handled through the construction life cycle under the design method and control standard which compensate for the problem of 3D data use and leverage the advantage maximally.

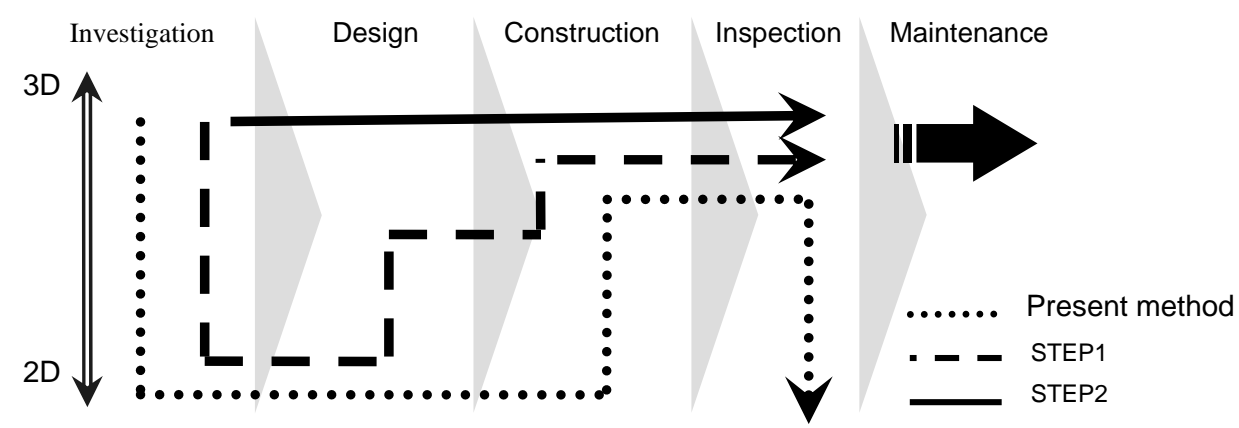

Fig.1 Data management in the construction process 


\section{PROPOSAL OF INSPECTION METHODS OF WORKING FORM USING 3D-DATA}

\section{(1) Method and problem of current inspection}

\section{a) Outline of inspection of working form}

In this study, we focus on the inspection method of working form to improve its effectiveness by using 3D data. In general, clients show 2D data such as the planes, the transverse sections, the elevation and so on. Then contractors construct structures based on these drawings. The working form of the constructed structure is operated by three persons: project manager, supervisor and field inspector (Table.1). The construction accuracy of the structure must satisfy the standard value of control standard.

\section{b) Measurement method}

The measurement method of each inspection items are shown in Table.2.

\section{c) Current problem}

On daily management and the inspection of working form, project manager and supervisor have to use various measurement equipments. Because these are different in each inspection items like height, extension and inclination. Furthermore since surveying values are recorded in field book by hand, project manager and supervisor have to transcribe these values to report like control chart of working form. Therefore transcription mistakes are happen and interfere with daily work.

The supervisor has to watch construction sites in the visual. Therefore it is difficult to supervise the condition of daily working form inspection if he has many construction sites and remote sites.

Table.1 Inspection contents of each

\begin{tabular}{|c|l|l|}
\hline \multirow{2}{*}{ Client } & Supervisor & $\begin{array}{l}\text { To supervise whether the structure } \\
\text { satisfied the standard of the } \\
\text { operation item of working form. }\end{array}$ \\
\cline { 2 - 4 } Contractor & Field inspector & $\begin{array}{l}\text { To do inspection of working form } \\
\text { and inspects whether the structure } \\
\text { limited the standard value of the } \\
\text { control criteria. }\end{array}$ \\
\hline & $\begin{array}{l}\text { To operate construction accuracy } \\
\text { about shape of structure as an } \\
\text { operation of working form } \\
\text { everyday. }\end{array}$ \\
\hline
\end{tabular}

There are problems of sharing working form data between clients and contractors.

\section{(2) Proposal of new inspection method}

In this study, we propose two inspection methods of working form using $3 \mathrm{D}$ data as follows.

\section{a) Distance calculating method (DCM)}

The concept is based on STEP1 in Chapter 2. The purpose is following three points.

(1) Introduction of 3D data management which is suited to current design method and control standard.

(2) Unifying the measurement data.

(3) Sharing working form data between clients and contractors.

DCM is the method of comparing with design data and calculated data. Calculated data is conputed to height, extension and inclination from 3D data using TS. Moreover the working form data is shared between clients and contractors by Web system.

TS is the measurement equipment that is integrated with the transit and the stadimeter. It can measure horizontal angle, angle of elevation, and slope distance. Its ranging accuracy is $2 \mathrm{~mm}+\mathrm{L} \times 2 \mathrm{ppm} \sim 5 \mathrm{~mm}+\mathrm{L} \times 2 \mathrm{ppm}(\mathrm{L}$ : Length). In the TS survey, a Mirror man locates mirror to measure point. Then it measures 3D location information by light wave from the TS and analyzing reflection from the mirror. It is compatible with PC. Therefore the TS survey is becoming the major method for topographic survey. There is RTK-GPS survey can measure 3D data too. But its cost is too expensive to bring in small-and-medium-size construction site. Then the TS

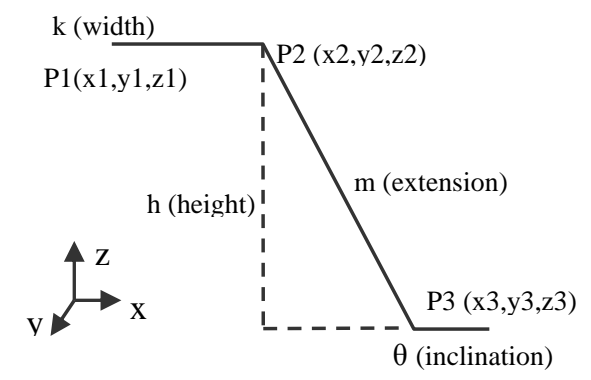

Fig.2 Calculation by coordinate data

Table.2 Measurement method of each operation item

\begin{tabular}{|c|c|c|c|c|}
\hline Operation item & Height & Width & Extension & Inclination \\
\hline Tool & Level, Staff & Tape measure, Measure, Staff & Tape measure, Measure, Staff & Inclination measure \\
\hline The number of worker & More than 2 people & More than 3 people & More than 3 people & More than 2 people \\
\hline & & & & \\
Measurement condition & & & & \\
& & & & \\
\end{tabular}


survey is generally used in local construction.

The method of calculating each items from 3D data is shown in Fig.2.

(1) h (height): The difference of elevation is calculated between two points from z-coordinate of P2 and P3.

(2) $\mathrm{k}$ (width): The distance is calculated between two points from X-Y coordinate of P1 and P2.

(3) $\mathrm{m}$ (extension): The distance is calculated between two points, from $\mathrm{X}-\mathrm{Y}-\mathrm{Z}$ coordinate of $\mathrm{P} 2$ and $\mathrm{P} 3$.

(4) $\theta$ (inclination): The inclination angle is calculated between two points from $\mathrm{X}-\mathrm{Y}-\mathrm{Z}$ coordinate of $\mathrm{P} 2$ and $\mathrm{P} 3$.

\section{b) Coordinates comparing method (CCM)}

CCM is based on STEP2 in Chapter 2. The purpose is the following two points.

(1) Setting control items leveraged 3D data to improve all processes in construction life cycle (Fig1).

(2) Visualizing 3D data.

CCM needs to calculate distance from 3D data. The current standard control items are height and width etc. These items are very easy to understand for workers. Our proposal compared using 3D data simplifies inspection items and improves the inspection construction effectiveness. But compared with current items, it is hard to understand proposed one intuitively. Therefore we visualize 3D data using Web3D.

CCM compares 3D coordinate of corresponding points and estimates distance and direction gap between design and working form. There are three directions: the direction normal to the revetment (x), the direction parallel to the revetment (y), the direction to upward (z). About distance gap, we set standard value (radius of sphere is $\varphi$ ) around design coordinate value. When there is surveying value inside standard value, it passes the inspection (Fig.3).

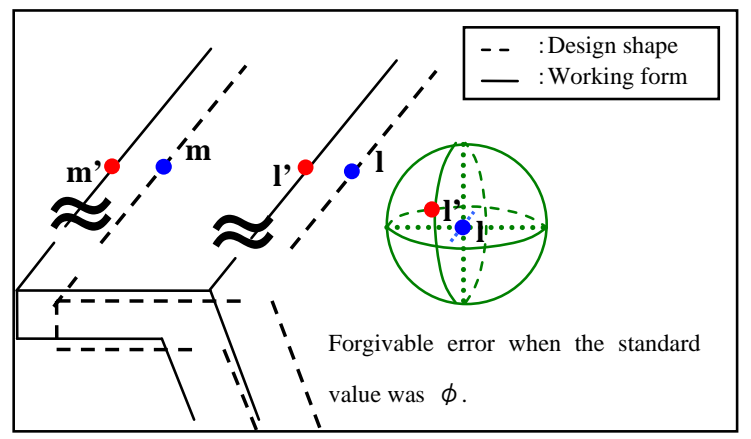

Fig.3 Image of CCM

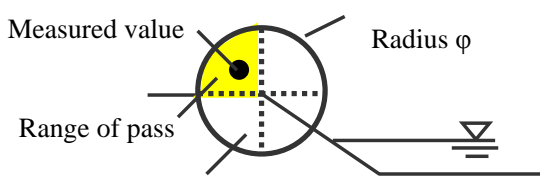

Fail

Fig.4 e.g. Standard value
About the direction gap, for example top of slope at left revetment, we set standard value like Fig.4. Because revetment should be higher and wider than design.

\section{EXPERIMENT}

\section{(1) Outline of the experiment}

\section{a) Purpose of the experiment}

The purpose of this experiment is to show effectiveness and possibility of proposed methods by comparing with current methods on same conditions. The experiment items are as follows.

(1) Measurement method using TS

(2) DCM

(3) CCM

(4) Sharing working form data using Web

\section{b) Outline of the construction site}

The experiment is carried out in the disaster recovery project at the Yunoura river. Outline of the construction (Table.3), the plane (Fig.5), the transverse section (Fig.6), and pictures of construction site (Fig.7) are shown.

\section{c) Process of the experiment}

Process of the experiment for evaluation is as follows.

(1)Calculation of coordinate data of design value

The revetment slope line is not parallel to the river centerline. Therefore coordinate data of design value is calculated by following method. First, the cross point of the traverse direction line and the revetment slope line is calculated from the plane. It is the base point. Second, the normal line against the revetment slope line is determined as the control direction line. Third, $\mathrm{X}-\mathrm{Y}$ coordinate are obtained by calculating distance of horizontal direction from the toe of revetment of the transverse section. Finally, $\mathrm{Z}$ coordinate is obtained from the transverse section.

Table.3 Outline of the site

\begin{tabular}{|l|l|}
\hline Construction site & $\begin{array}{l}\text { Okawachi Ward, Ashikita Town } \\
\text { Ashikita Country, Kumamoto }\end{array}$ \\
\hline Name of river & Yunoura river (Level 2) \\
\hline Date of disaster & $2003.07 .17 \sim 07.22$ \\
\hline Range & $8 \mathrm{k} 400 \sim 8 \mathrm{k} 520$ (Left bank) \\
\hline Length & $120 \mathrm{~m}$ \\
\hline Operation section & 12 sections \\
\hline
\end{tabular}




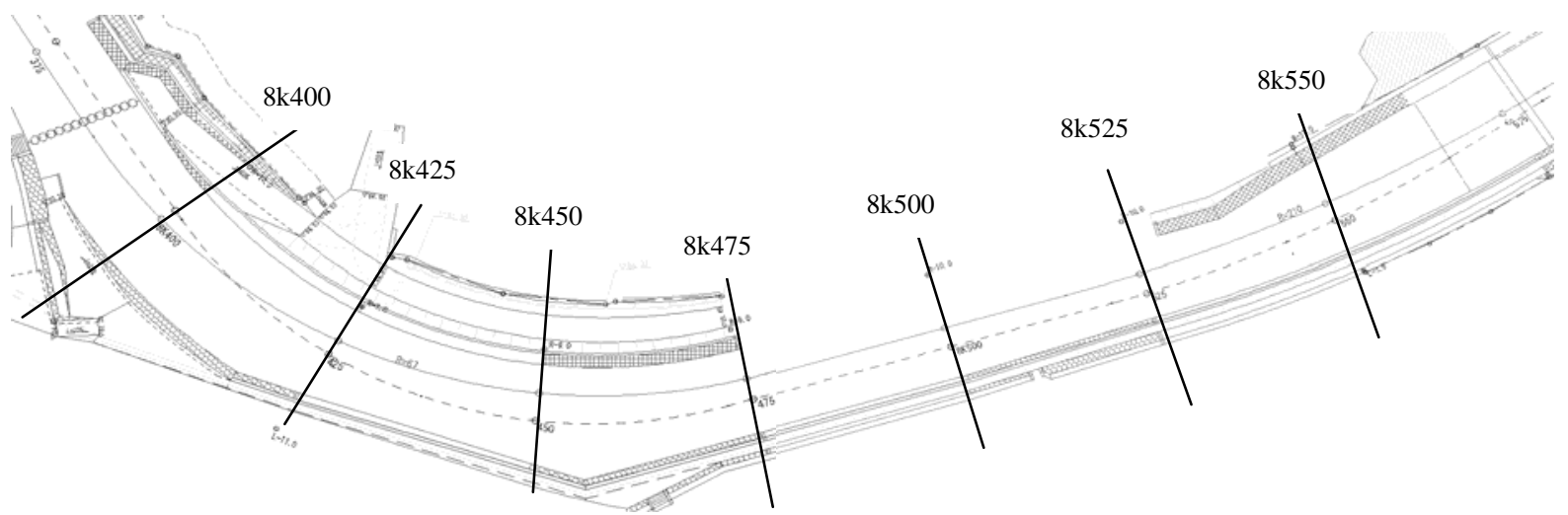

Fig.5 Plan of construction site

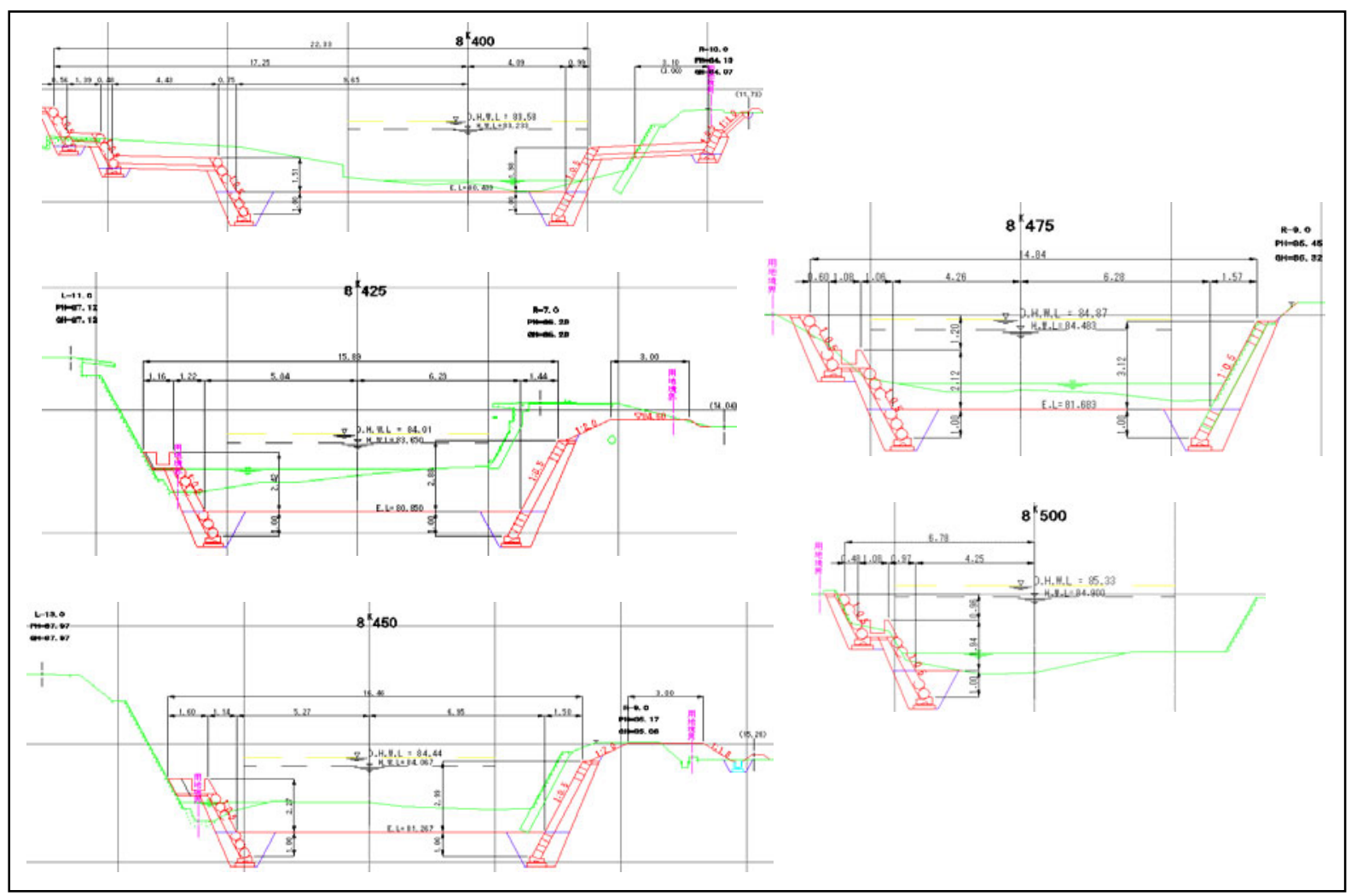

Fig.6 Transverse sections of construction site

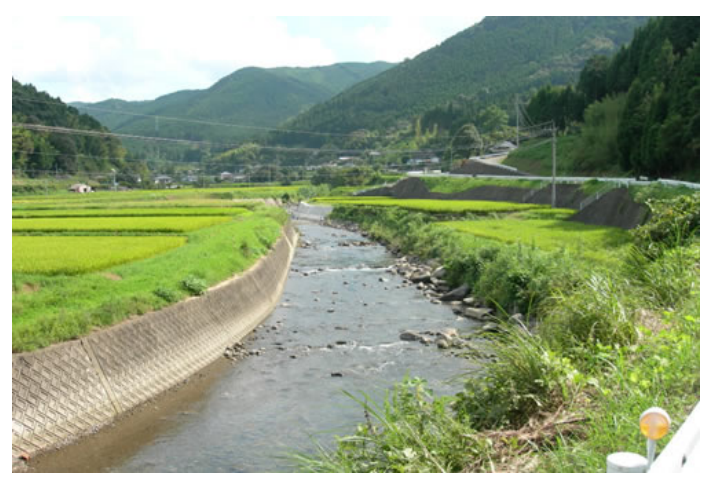

(a) Before

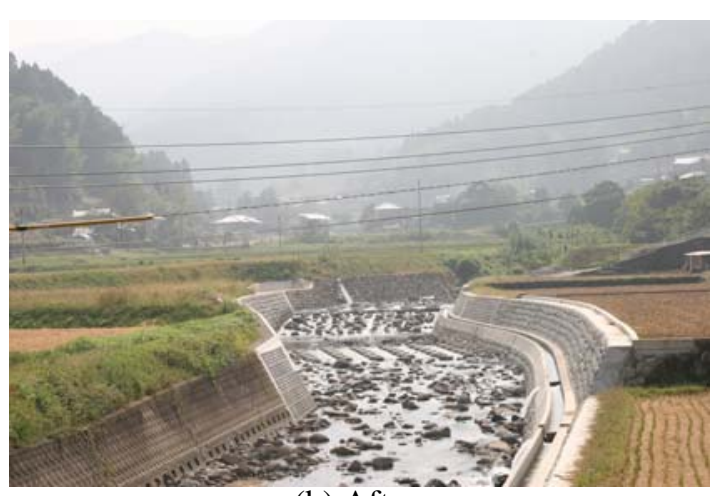

(b) After

Fig.7 Photograph of construction site 
(2) Getting coordinate data of actual value by the TS survey

Table.4 shows the control standard ${ }^{7}$ which compared DCM with the current method.

(3) Sharing working form data

The data sharing is carried out by the Web based working form control system.

\section{d) Function of the Web based working form control system (WWFC)}

Outline of WWFC is as follows (Fig.8).
Table.4 Control items

\begin{tabular}{|c|l|l|}
\hline Object item & Measurement item & \multicolumn{1}{c|}{ Standard value } \\
\hline \multirow{2}{*}{$\begin{array}{c}\text { Excavation for } \\
\text { foundation }\end{array}$} & Width & $\geqq$ Designed value \\
\cline { 2 - 3 } Quarrying & Height & $\geqq$ Designed value \\
\hline \multirow{2}{*}{ Base concrete } & Width & $\geqq$ Designed value \\
\cline { 2 - 3 } Revetment & Thickness & $-30 \mathrm{~mm}$ \\
\hline \multirow{3}{*}{ Height } & $\pm 30 \mathrm{~mm}$ \\
\cline { 2 - 3 } & Length & $-50 \mathrm{~mm}$ \\
\cline { 2 - 3 } & Length & $-100 \mathrm{~mm}$ \\
\hline Natural concrete & Height & $\pm 10 \%$ \\
\hline
\end{tabular}

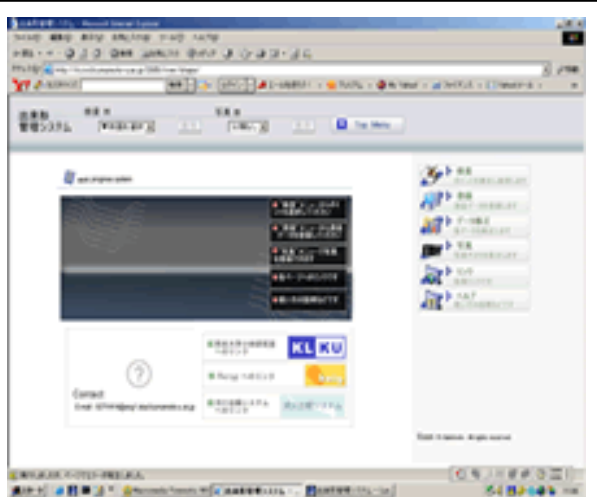

(a) Top screen

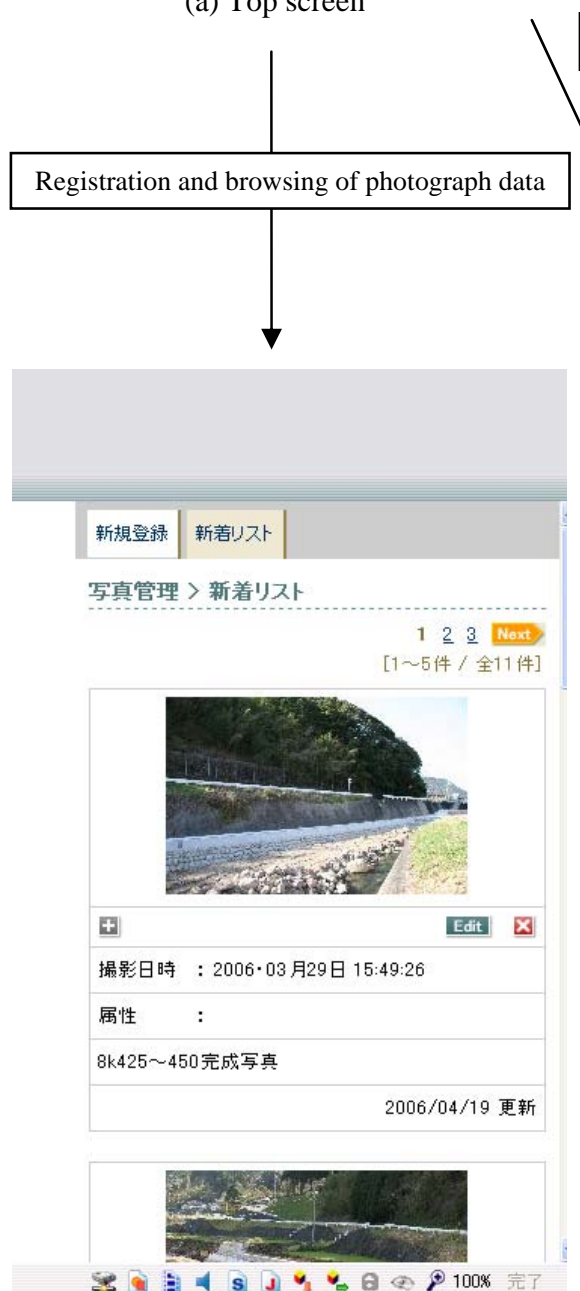

(d) Photograph browsing screen
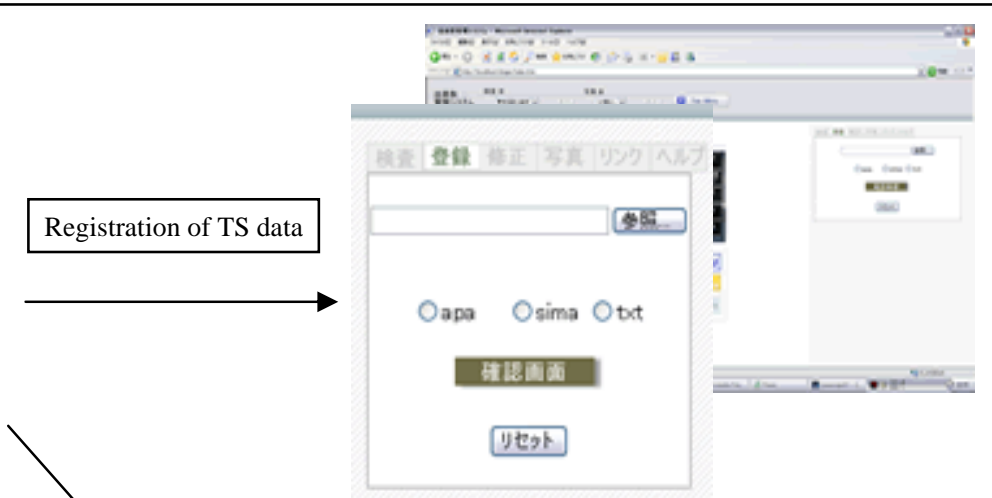

(b) Registration screen

Browsing of registered data

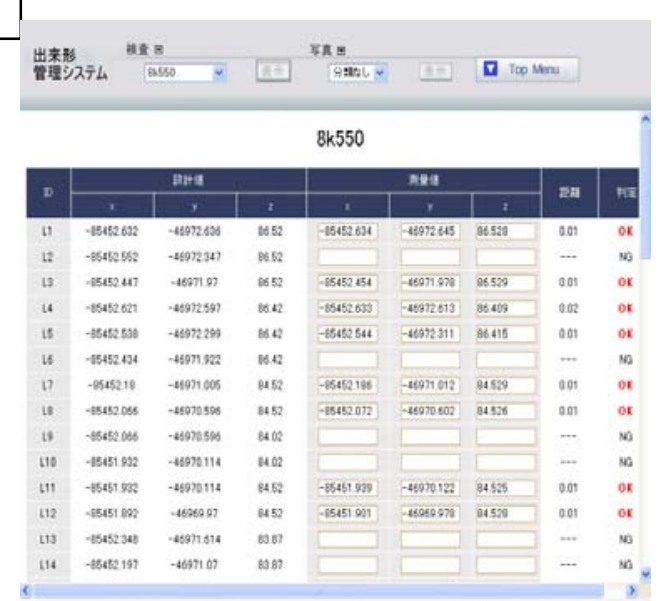

(c) Inspection screen

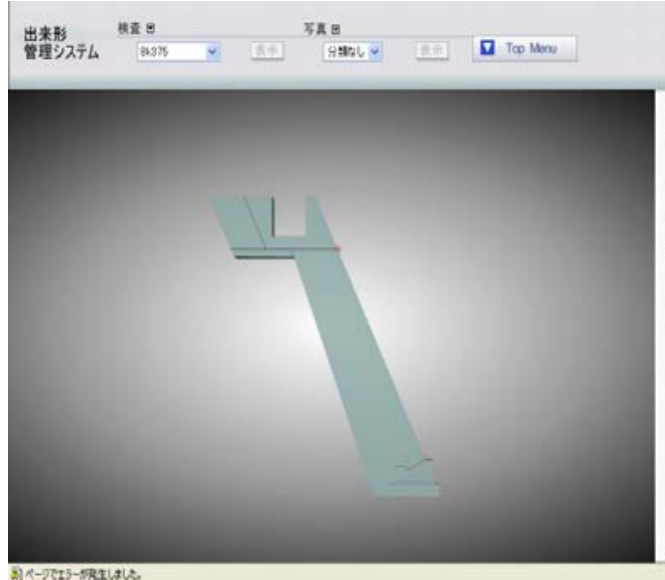

(e) Web3D screen

Fig.8 Outline of Web-Working form operation system 


\section{(1)Registration of data}

The surveying data and the photograph data can be uploaded to WWFC by system. As for the surveying data, this system can register the batch data in each transverse sections by writing to TS's external memory. The format of the data is SIMA or APA.

(2)Browse of the working form data

The list of registered design value corresponding to surveying value is displayed by selecting the section.

(3)Browse of the construction site photograph

The construction site photograph registered in each section is browsed by selecting the section.

\section{(4)Display of Web3D}

The 3D coordinate of the design value, the surveying value and the design shape are displayed in Web3D. Cult3D is used as a development tool. The 3D design shape is made from the transverse section using 3DCAD and is transferred into Cult3D.

\section{(2) Result of the experiment}

\section{a) Result of DCM and the current method}

Fig.9 shows the result of extension, inclination and height in the revetment which compared current method with DCM. Those graphs represent that standard value and difference of the design value and the surveying value in each measurement items when the inspection of working form is done by current method and DCM. The ordinate shows a difference and the abscissa show a mile post.

\section{b) Result of CCM}

The Web3D can display the control section and switch the display from front or back side view, left or right side view and upper or lower side view by keyboard operation. Therefore it can rotate, move and zoom the display by mouse operation (Fig.10). The surveying value, the design value and the design shape which are corresponding to control items of the DCM are displayed by Web3D. The control standard is $5 \mathrm{~cm}$ to each direction and is determined a sphere with $10 \mathrm{~cm}$ diameter. Therefore the design value and the surveying value of the construction of revetment are displayed as a sphere with $1 \mathrm{~cm}$ diameter. Inspection results which pass or fail the inspection can be confirmed by color of these spheres. The example of the results of display is shown in Fig.11.

\section{(3) Discussion}

\section{(1)Measurement method using TS}

Some hearing research about the result of experiment from project manager, supervisor and field inspector were carried out at Kumamoto University.
They answered: The improvement of the construction effectiveness was achieved at some level by unifying the measurement equipments in a working form control. In the future, more experiments will be necessary to achieve the improvement of the construction effectiveness by calculating a number of worker and elapse time and comparing the current method with the proposed method.

The spreadsheet was used for calculating of the design value coordinate data on this experiment. There is, however, room for improvement. For example, the coordinate is calculated by relating the plane with each transverse sections on 3DCAD.

DCM will become more efficiency by improving the control method of the data flow through design, construction and inspection.

Fig.12 shows the average absolute value which is error between the design of height and the actual height on each mile post in the level survey and TS survey. The height is measured from the fixed point and the temporary bench mark is set. The temporary bench marks are set near the point No. k450 in this construction site. In current method the distance becomes farther, the error becomes larger.

\section{(2)DCM}

The difference of the current method and DCM is limited in about $\pm 2 \mathrm{~cm}$ (Fig.13). There are three spots whose difference are more than $\pm 5 \mathrm{~cm}$. Those are, however, $4 \mathrm{~cm}$ difference between 2D design value (got from current transverse section) and 3D design value (got from calculating 3D coordinate). That difference is created by the distortion in creating 2D plane and by rounding up or off fractions of design value. Then it is created by not only the inspection method. The difference of design value which was calculated by current method and DCM is limited in range of control standard in this construction site (Fig.9). Then there are no influence of the result which pass or fail the inspection of working form.

\section{(3) CCM}

The standard value is set to each $x-y-z$ direction. It is a sphere with $10 \mathrm{~cm}$ diameter. Then whether the difference between the design value and the surveying value satisfy the standard value is confirmed visually by displaying on the Web3D. In the future, supervisor and field inspector will be able to confirm the working form conditions not current control items but proposed items. The construction effectiveness can be improved by confirming the surveying value of two points because some items height, extension and inclination are calculated. Moreover the visualization of invisibility part like excavation for foundation is also effective. 


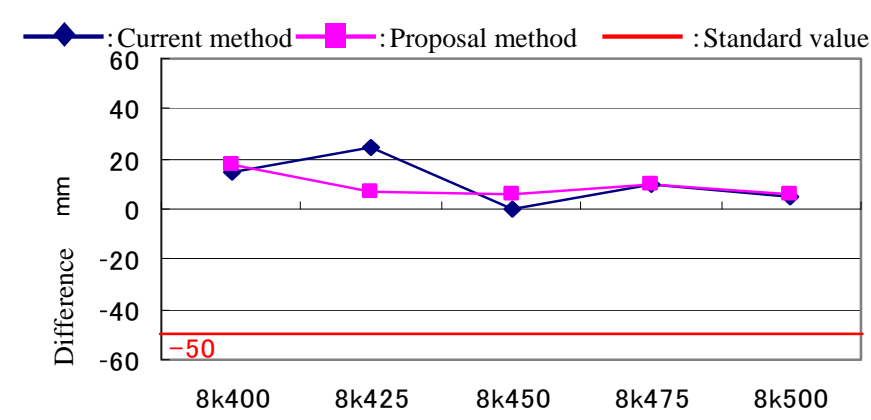

(a) Comparative result (Extension of shore protection)

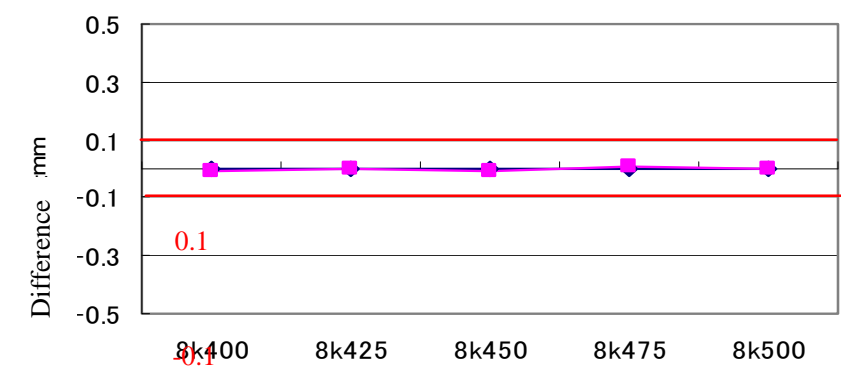

(b) Comparative result (Inclination of shore protection)

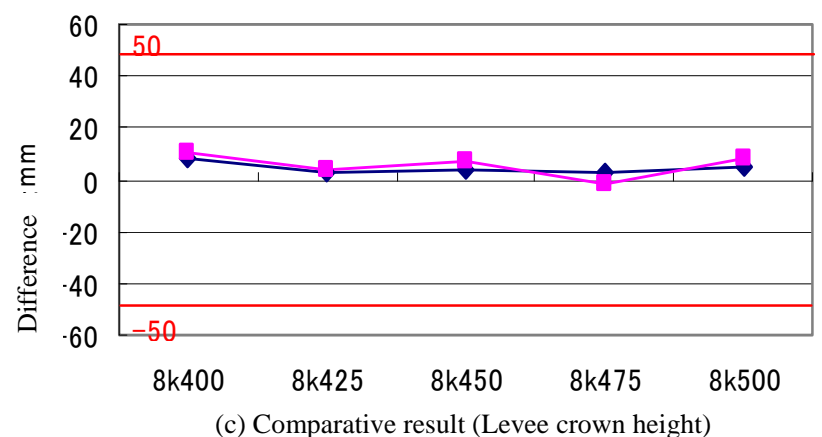

Fig.9 Comparative result of each operation item

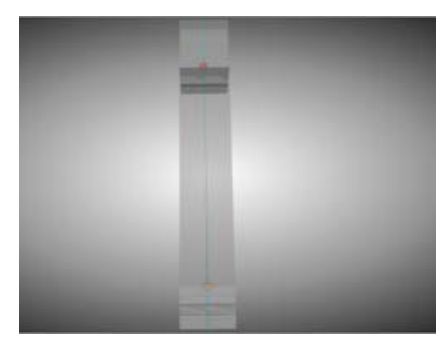

(a) Front side view

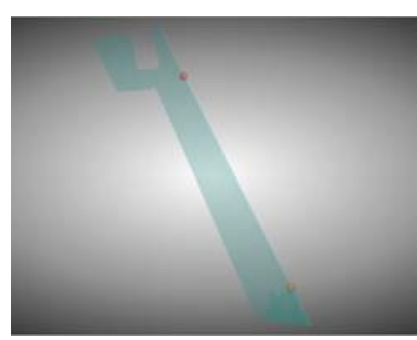

(b) Operation section

Fig.10 Operating of Web3D

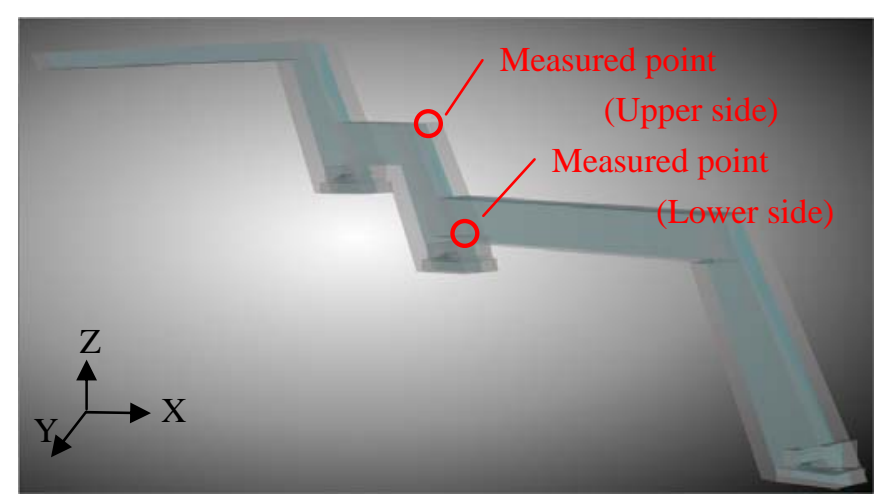

(a) The entire of designed shape

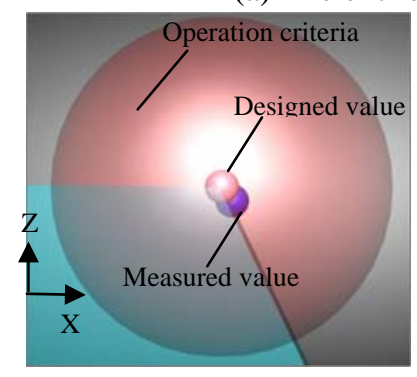

(b) Zoom of transverse direction (Upper side)

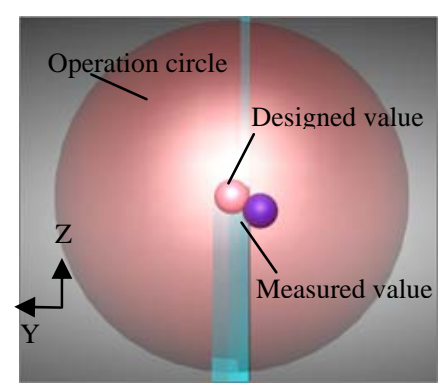

(d) Zoom of front direction (Upper part)

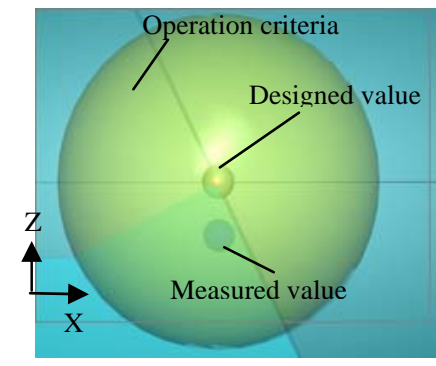

(c) Zoom of transverse direction (Lower side)

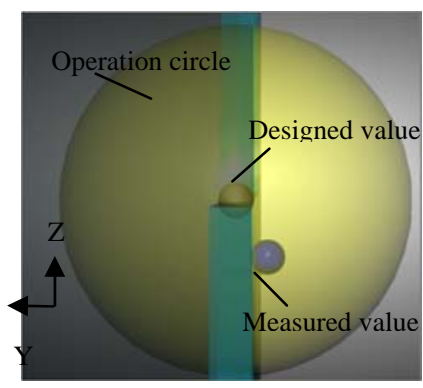

(e) Zoom of front direction (Lower side)

Fig.11 Display of result 


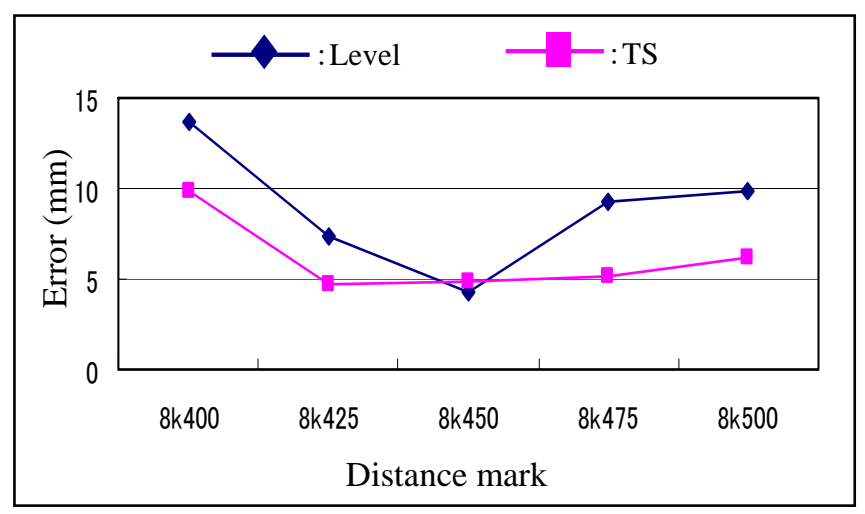

Fig.12 Error of level survey and TS survey

(4) Sharing working form data by Web

The data, such as the design value, the surveying value and construction site photographs are shared between clients and contractors on the Web system. Supervisor can confirm condition of construction site by browsing the Web3D. If he has many construction sites and remote sites at the same time, the Web3D is very effective to his daily work.

\section{CONCLUSION}

The characteristics of river works were analyzed and the inspection of working form was researched for the 3D data control through the construction life cycle. For the purpose of the dissemination of 3D data, DCM which was suited to current control standard and design method was proposed. Then the efficiency improvement of the inspection work was done by unifying measurement equipment on the TS survey. Therefore CCM which included review of control standard was proposed. The possibility of further efficiency improvement of the work by the visualization of 3D data using Web3D was confirmed and the review of control standard was proposed. Moreover the effectiveness of TS survey and the reliability of the method were proven by comparing result of the current method and DCM in the experiment. CCM could confirm the working form conditions by displaying the acquired data in Web3D. In the future, we need to verify effectiveness of CCM including new standard values.

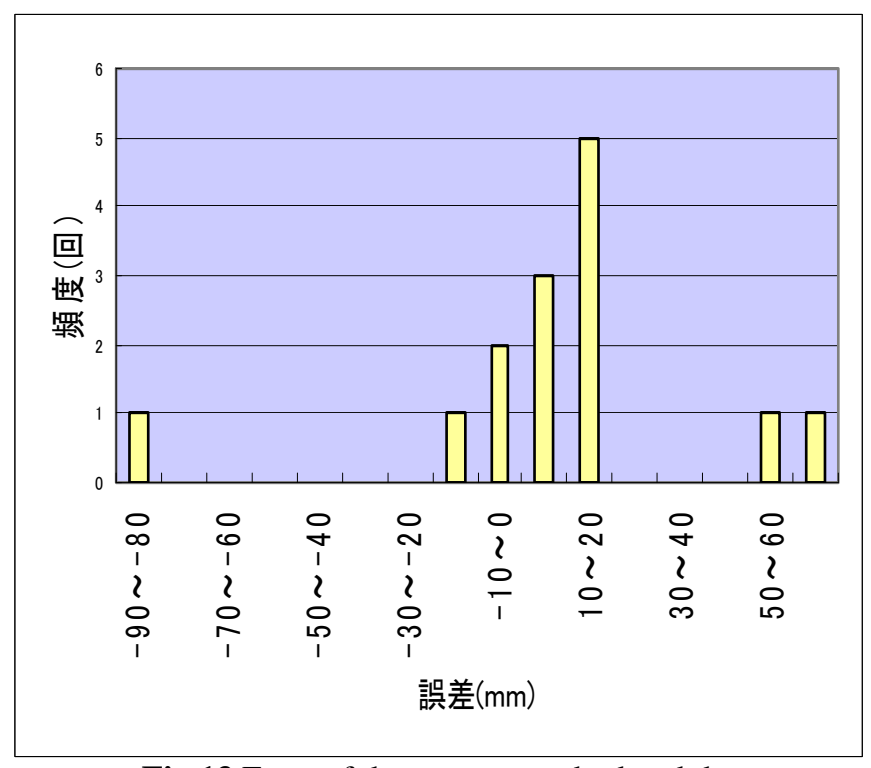

Fig.13 Error of the present method and the inspection method of calculating distance

Acknow ledgments : The writers would like to express their gratitude to Ashikita Regional Promotion bureau of Kumamoto prefectural government.

\section{Reference}

1) Progress control of working form points with total station where construction management data is installed (Idea) (Chapter of road navvy) (In Japanese)

<http://www.mlit.go.jp/kisha/kisha07/01/010406_2/02.pdf> (accessed 2007. 05).

2) Verified experiment of Road Working-form Management by using IT Technology: Journal of Applied Computing in Civil Engineering, Vol. 13, pp. 251-260 (In Japanese)

3) A New Method to Progress Control of Working Form in Paving Work by using Information Technology: Journal of Applied Computing in Civil Engineering, Vol. 14, pp. 231-238 (In Japanese)

4) A New Method for Surface Management of Paving Working-form using Laser Scanning System : Journal of Applied Computing in Civil Engineering, Vol. 15, pp. 249-258 (In Japanese)

5) Method of Confirming Construction Phase by Using Webcam and Survey Data : Journal of Applied Computing in Civil Engineering, Vol. 15, pp. 241-248. (In Japanese)

6) A New Method to Progress Control of Working Form in Embankment and Revetment Work by Using 3D-Data : JOURNAL OF STRUCTURES AND MATERIALS IN CIVIL ENGINEERING, No.22, pp. 145-154. (In Japanese)

7) Control standard : Kumamoto Prefecture earthwork construction control standard (In Japanese)

$<$ http://www.pref.kumamoto.jp/construction/section /doboku/kijyun/index.html > (accessed 2007.05). 